\title{
LETTER
}

\section{Glucocorticoids inhibit type I IFN beta signaling and the upregulation of CD73 in human lung}

\author{
Juho Jalkanen' ${ }^{1}$ Ville Pettilä2 ${ }^{2}$ Teppo Huttunen ${ }^{3}$, Maija Hollmén ${ }^{4}$ and Sirpa Jalkanen ${ }^{4,5^{*}}$ (D)
}

(c) 2020 The Author(s)

Dear Editor,

Glucocorticoids are widely used to treat acute respiratory distress syndrome (ARDS) despite their use being highly controversial based on randomized controlled trials and meta-analyses [1]. As type I interferons (IFNs) are our first line of defense against severe viral respiratory infections, we explored whether glucocorticoids interfere with IFN signaling and whether their use associates with outcome of IFN beta treatment of ARDS.

Methods are described in the eSupplement. We performed a propensity-matched post hoc analysis using data from the recent randomized INTEREST trial comparing IFN beta-1a to placebo in ARDS patients [2]. Seventy-eight out of 144 patients (54\%) included in the IFN beta-1a treatment arm of the INTEREST trial received glucocorticoids during the 28-day study period, $56 \%(44 / 78)$ at randomization (D0), $27 \%$ (21/78) during the treatment (D1-6) and 17\% (13/78) after the treatment (D7 onward). Day-28 mortality for patients receiving glucocorticoids with IFN beta-1a was $39.7 \%$ compared to $10.6 \%$ for patients receiving IFN beta-1a alone. The Kaplan-Meier curves of the IFN beta-1a treatment arm adjusted by ARDS severity and divided according to the overlapping (D0-D6) use of glucocorticoids with IFN beta-1a treatment demonstrate significantly increased mortality by glucocorticoid use ( $p=0.0002$, see supplement).

In the post hoc propensity-matched analysis of the IFN beta-1a arm $(n=144)$, baseline systemic glucocorticoid treatment was independently associated with D28 mortality (OR 5.4, 95\% CI 2.1-13.9, $p<0.001$ ) according to logistic regression. When the propensity-matched analysis was performed using an exact matching (a precision of 0.01 propensity units), there were 49 pairs of patients who received or did not receive glucocorticoids $(n=98)$. Among these patients, OR for increased mortality was 4.6 (95\% CI 1.6-13.5) for those who had baseline systemic glucocorticoid treatment and 3.5 (95\% CI 1-12) for those who initiated glucocorticoid treatment while receiving IFN beta-1a (Fig. 1a).

Based on the results of these analyses, we utilized human lung tissue and pulmonary endothelial cell cultures to investigate the effect of hydrocortisone on IFN nuclear signaling and the protein transcription of CD73, a molecule responsible for vascular integrity and leukocyte infiltration to sites of inflammation [3].

When IFN beta-1a was applied to the lung organ cultures, CD73 expression was upregulated. However, in the presence of hydrocortisone, CD73 upregulation was inhibited (Fig. 1b, c). IFN beta-1a signaling via its receptor leads to the formation of a heterotrimeric transcription complex ISGF3 containing STAT1-STAT2 and IRF9, which then enters the nucleus and binds to the IFN beta responsive elements of several genes or assembly on DNA [4]. In pulmonary endothelial cell cultures, IFN beta-1a induced the translocation of IRF9 
A

\begin{tabular}{|c|l|c|}
\hline & Factor & OR $(95 \% \mathrm{Cl})$ \\
\hline i & Propensity for baseline corticosteroids (per 0.01) & $1.04(1.01-1.07)$ \\
\hline & Corticosteroids at trial baseline & $5.35(2.06-13.93)$ \\
\hline & New corticosteroids after randomization & $3.88(1.18-12.73)$ \\
\hline & ARDS severity (severe vs moderate) & $1.21(0.43-3.42)$ \\
\hline & & \\
\hline ii & Corticosteroids at trial baseline & $4.59(1.56-13.48)$ \\
\hline & New corticosteroids after randomization & $3.50(1.03-11.96)$ \\
\hline
\end{tabular}

B

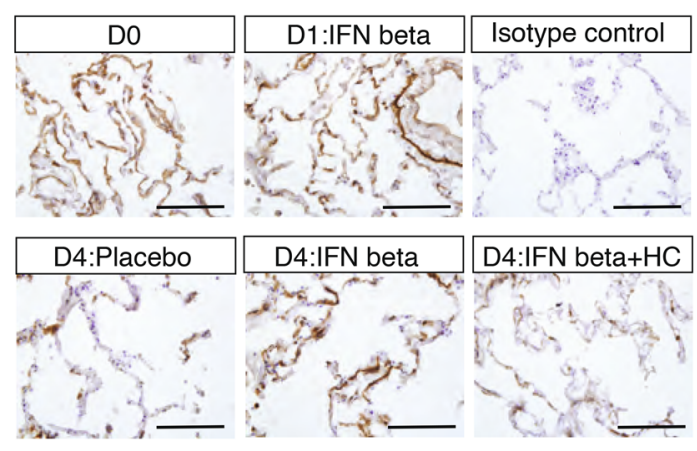

C

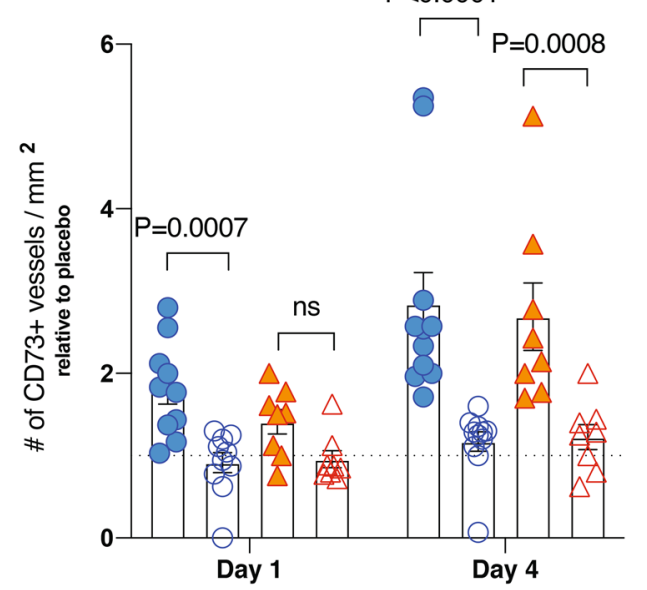

D
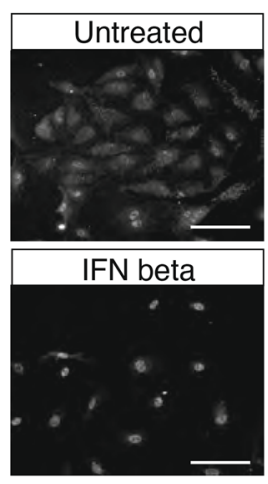

E

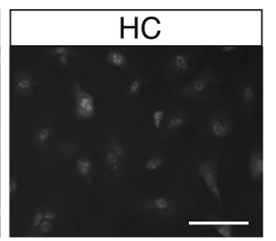

IFN beta+HC

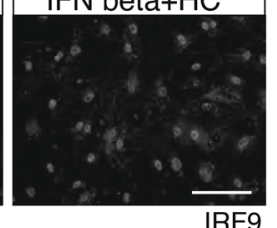

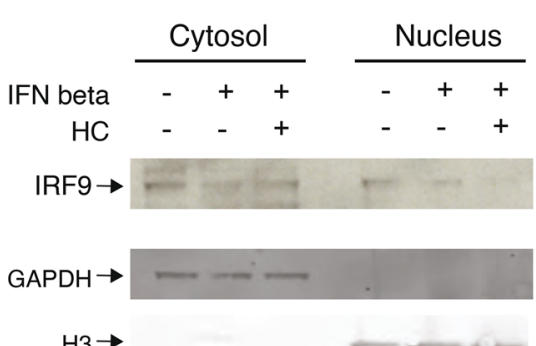

F

$\mathrm{H} 3 \rightarrow$
- FP-1201

O $\mathrm{FP}-1201+\mathrm{HC}$

$\triangle \mathrm{DS}$

$\triangle \mathrm{DS}+\mathrm{HC}$
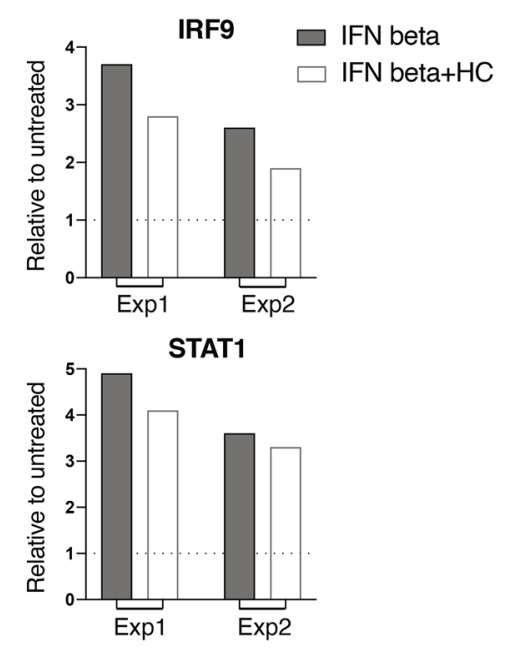


\section{(See figure on previous page.)}

Fig. 1 Glucocorticoid use associates with mortality and blunts IFN beta-induced CD73 upregulation in lung vasculature and IFN beta-1a dependent signaling pathways in pulmonary endothelial cells. a (i) Independent factors associated with Day 28 mortality in all IFN beta-1a-treated patients $(n=144)$ by logistic regression adjusted for propensity score and ARDS severity (odds ratios, OR with $95 \%$ confidence intervals, CI). (ii) Association of glucocorticoid treatment with D28 mortality in only propensity-matched IFN beta-1a-treated patients $(n=98)$ by logistic regression (OR with $95 \%$ Cl) b Immunohistochemical staining of CD73 (brown) in lung tissue incubated in the presence of IFN beta with or without hydrocortisone (HC) for 1 and 4 days (D). D0 indicates baseline expression of CD73 in fresh lung tissue. c Quantification of CD73 positive vessels $/ \mathrm{mm}^{2}$. The samples were incubated in the presence of two different IFN beta-1a formulations (FP-1201, circles $n=10$ (day 1) and $n=11$ (day 4); DS, triangles $n=8$ ). Each data point marks an individual. The dotted line represents the placebo-induced level of CD73 expression. Statistical significance was analyzed using the Mann-Whitney test. $\mathbf{d}$ Immunofluorescence staining of IRF9 in primary human pulmonary endothelial cells after IFN beta treatment with or without $\mathrm{HC}$ showing marked inhibition of nuclear translocation of IRF9 by HC, the representative results of three independent experiments with the similar results. e Immunoblotting of the cytosolic and nuclear fractions of pulmonary endothelial cells after IFN beta-1a \pm HC demonstrating both decreased IRF9 signal and its nuclear translocation. Specific IRF9 band is indicated by an arrow, a representative blot of five independent analyses with the comparable results. GAPDH and $\mathrm{H3}$ (histone) are loading controls for the cytoplasmic and nuclear fractions, respectively. $\mathbf{f}$ qPCR results of two independent experiments demonstrating the decrease in IFN beta-1a-triggered mRNA synthesis of IRF9 and STAT1 by HC. Scale bars $100 \mu \mathrm{m}$

into the nucleus, which was reduced by hydrocortisone treatment (Fig. 1d, e). In addition, hydrocortisone treatment decreased IRF9 and STAT1 mRNA synthesis when measured by qPCR (Fig. 1f), which was also seen at the protein level in Fig. 1d.

We conclude that glucocorticoids inhibit type I IFN beta signaling and the upregulation of CD73 in human lung. This provides the mechanistic basis for the harmful association of glucocorticoids in IFN beta-treated patients in the INTEREST trial. This study takes the earlier preclinical evidence that steroids block endogenous IFN signaling [5] to the critical care setting. Our findings give mechanistic support to the ICM recommendation not to use glucocorticoids at the early stages of severe COVID-19 or viral-induced ARDS in general and highly recommends not to use systemic glucocorticoids together with type I interferons because of the harmful effects of this combination.

\section{Electronic supplementary material}

The online version of this article (https://doi.org/10.1007/s00134-020-06086-3) contains supplementary material, which is available to authorized users.

\section{Author details}

${ }^{1}$ Faron Pharmaceuticals Ltd, Turku, Finland. ${ }^{2}$ Department of Anesthesiology, Intensive Care and Pain Medicine, University of Helsinki and Helsinki University Hospital, Helsinki, Finland. ${ }^{3}$ 4Pharma Ltd, Turku, Finland. ${ }^{4}$ Medicity Research Laboratory, University of Turku, Turku, Finland. ${ }^{5}$ Institute of Biomedicine, University of Turku, Turku, Finland.

\section{Acknowledgements}

We thank Riikka Sjöroos and Sari Mäki for expert technical assistance and the study group of the INTEREST trial for participating to the study at the trial sites. The work was funded by Academy of Finland, Faron Pharmaceuticals Ltd, European Union Seventh Framework Program (Grant Agreement No. 305853).

\section{Authors' contribution}

$\mathrm{KE}, \mathrm{MH}$ and $\mathrm{SJ}$ contributed to the experimental study design and analyzed the results of the experiments. JJ, VP, MK, JM, MJ, GB and VMR contributed to the original INTREST trial and to the post hoc analyses presented in this paper. MM consented the patients donating the lung specimens and performed the surgical operations. TH performed the statistical analyses. JJ, VP and SJ wrote the first draft of the manuscript. All authors contributed to its' final version.
Members of the study group (sub authors): Matti KARVONEN, MD PhD, Jami MANDELIN, PhD, Markku JALKANEN, PhD, Markus MALMBERG, MD PhD, Kati ELIMA, MD PhD, Geoff BELLINGAN, MD PhD, V. Marco RANIERI, MD PhD.

\section{Data availability}

After publication, the data and the novel reagent (anti-CD73 antibody) will be made available to others on reasonable requests to the corresponding author.

\section{Compliance with ethical standards}

\section{Conflicts of interest}

$J \mathrm{~J}$ is an employee and shareholders of Faron Pharmaceuticals. MH and SJ own stocks of Faron Pharmaceuticals and SJ has a patent (US 7534423).

\section{Ethics approval and consent to participate}

All procedures performed in studies involving human participants in the original INTEREST trial (ClincalTrials.gov Identifier NCT02622724) were in accordance with the ethical standards of the institutional and/or national research committees and the Helsinki declaration.

\section{Open Access}

This article is licensed under a Creative Commons Attribution-NonCommercial 4.0 International License, which permits any non-commercial use, sharing, adaptation, distribution and reproduction in any medium or format, as long as you give appropriate credit to the original author(s) and the source, provide a link to the Creative Commons licence, and indicate if changes were made. The images or other third party material in this article are included in the article's Creative Commons licence, unless indicated otherwise in a credit line to the material. If material is not included in the article's Creative Commons licence and your intended use is not permitted by statutory regulation or exceeds the permitted use, you will need to obtain permission directly from the copyright holder.To view a copy of this licence, visit http://creativecommons.org/licen ses/by-nc/4.0/.

\section{Publisher's Note}

Springer Nature remains neutral with regard to jurisdictional claims in published maps and institutional affiliations.

Accepted: 4 May 2020

Published online: 19 May 2020

\section{References}

1. Ruan SY, Lin HH, Huang CT, Kuo PH, Wu HD, Yu CJ (2014) Exploring the heterogeneity of effects of corticosteroids on acute respiratory distress syndrome: a systematic review and meta-analysis. Crit Care 18:R63 
2. Ranieri VM, Pettilä V, Karvonen MK, Jalkanen J, Nightingale P, Brealey D, Mancebo J, Ferrer R, Mercat A, Patroniti N, Quintel M, Vincent JL, Okkonen M, Meziani F, Bellani G, MacCallum N, Creteur J, Kluge S, Artigas-Raventos A, Maksimow M, Piippo I, Elima K, Jalkanen S, Jalkanen M, Bellingan G, Group IS (2020) Effect of intravenous interferon $\beta$-1a on death and days free from mechanical ventilation among patients with moderate to severe acute respiratory distress syndrome: a randomized clinical trial. JAMA. https://doi. org/10.1001/jama.2019.22525

3. Thompson LF, Eltzschig HK, Ibla JC, Van De Wiele CJ, Resta R, Morote-Garcia JC, Colgan SP (2004) Crucial role for ecto-5'-nucleotidase (CD73) in vascular leakage during hypoxia. J Exp Med 200:1395-1405
4. Platanitis E, Demiroz D, Schneller A, Fischer K, Capelle C, Hartl M, Gossenreiter T, Müller M, Novatchkova M, Decker T (2019) A molecular switch from STAT2-IRF9 to ISGF3 underlies interferon-induced gene transcription. Nat Commun 10:2921

5. Flammer JR, Dobrovolna J, Kennedy MA, Chinenov Y, Glass CK, Ivashkiv LB, Rogatsky I (2010) The type I interferon signaling pathway is a target for glucocorticoid inhibition. Mol Cell Biol 30:4564-4574 